Mundo Agrario vol. 18, n 37, e048, abril 2017. ISSN 1515-5994

Universidad Nacional de La Plata.

Facultad de Humanidades y Ciencias de la Educación.

Centro de Historia Argentina y Americana

\title{
Territorio, Poder y Sojización en el Cono Sur latinoamericano. El caso argentino 1
}

\author{
Territory, power and soybean production in the Latin American \\ Southern Cone. The Argentine case
}

Mabel Manzanal *

* Consejo Nacional de Investigaciones Científicas y Técnicas Programa de Estudios Regionales y Territoriales, Instituto de Geografía, Facultad de Filosofía y Letras, Universidad de Buenos Aires, Argentina | mabelmanzanal@gmail.com

\section{PALABRAS CLAVE RESUMEN}

El presente trabajo discute la cuestión territorial de reprimarización de las economías latinoamericanas, en particular las del Cono Sur. Para ello, trabajamos con información secundaria, entrevistas a informantes calificados y resultados de investigación, vinculados esencialmente con la sojización en Argentina. Desde una perspectiva que Poder analiza el territorio, el poder y la construcción de hegemonía se descubren variadas situaciones que afectan la subsistencia de las poblaciones que viven de los recursos que están en disputa (tierra, agua, bosques). A través de Desarrollo este análisis se pone en evidencia que la actual forma de acumulación, extractivista y especulativa compromete el Sojizacion futuro de la sociedad en su conjunto. Y desconocerlo resulta funcional a los intereses de los sectores dominantes.

Argentina

Economía

Latinoamérica

\section{KEYWORDS}

Territory

Power

Development

Soybean production

Argentina

Economy

Latin America

\section{ABSTRACT}

This paper discusses territorial issues of re-primarization of Latin American economies, particularly those of the Southern Cone. It uses secondary information, interviews with qualified informants and research results, essentially linked to the expansion of soybean production in Argentina. From a conceptual perspective focused on territory and power, it uncovers various situations affecting the people livelihoods, especially of those living upon resources under dispute (land, water, forests). Under this light it shows that the current form of accumulation, which is extractive and speculative, affects the future of society as a whole. To neglect this is to be functional to the dominant sectors' interests. 


\section{Introducción ${ }^{2}$}

Avances alarmantes de deforestación, desertificación y pérdida de biodiversidad, con procesos consecuentes de marginación y persecución social conforman una preocupante realidad cada vez más extendida dentro del espacio latinoamericano.

La expansión del monocultivo y la producción a gran escala de agrocombustibles (soja, palma aceitera, maíz), la minería a cielo abierto, la intensificación de actividades industriales y agroindustriales contaminantes (y/o con escaso control y regulación, como la celulósica, la ganadería en feedlots ${ }^{3}$ ) están en el origen de estas problemáticas.

La promoción, ampliación y difusión de producciones con efecto regresivo -social, política y ambiental- se sostiene en un discurso hegemónico que afirma y publicita que la economía de la mayoría de los países del Cono Sur depende y necesita de estas actividades para garantizar su crecimiento y bienestar. De este modo se justifica, sostiene y consolida un modelo económico-productivo dominante, en el que las organizaciones y sectores sociales que se oponen son permanentemente cuestionados, judicializados y perseguidos con diferentes métodos, cuando no reprimidos, encarcelados y asesinados 4 .

Convivir, oponerse y enfrentarse al poder hegemónico y a sus variadas expresiones -económicas, políticas, financieras, culturales- es una tarea enorme que abarca diversos e infinitos frentes. Entre todos ellos, entendemos que el más complejo es el que se vincula con el discurso hegemónico que naturaliza hechos y realidades como los que aquí nos ocupan -vinculados con la expansión de los commodities- y que los expone como resultantes de un devenir natural y necesario para el bien de todos y para el desarrollo de la nación en cuestión. Esto es un discurso de poder, una construcción de verdad, la verdad del poder hegemónico que se conforma ocultando, desinformando, desvalorizando toda evidencia sobre las negativas consecuencias -sociales, ambientales, productivas y culturales- que estos procesos productivos conllevan.

Es este contexto cultural hegemónico el que logra que las actuales consecuencias de la producción del territorio $\underline{\underline{5}}$ y de valorización del capital (ligadas al extractivismo y a la reprimarización $\underline{6}$ de las economías del Cono Sur latinoamericano) se tornen lejanas e incomprensibles para la gran mayoría de la población. Porque se desconoce, se minimiza o se desestiman los problemas sociales, económicos, políticos y ecológicos resultantes del avance de los commodities, como: la profundización de la desigualdad y la marginación social, el deterioro ambiental proveniente de la deforestación y del uso de plaguicidas; la persecución, la opresión y la discriminación de numerosos actores involucrados, la pérdida de autonomía en las decisiones políticas, económicas, tecnológicas y financieras ${ }^{7}$.

Vale aclarar que algunos de estos procesos difieren en su profundidad, características y especificidad según nos refiramos a territorios pampeanos y extrapampeanos. Así, por ejemplo, ciertas formas de persecución y discriminación de poblaciones originarias o de ocupantes sin título aparecen concentradas en las áreas extrapampeanas. Lo mismo puede decirse de los actuales procesos de avance de la frontera agropecuaria y de deforestación. No es tan nítida esta diferenciación entre pampeano y no pampeano cuando nos ocupamos de los peligros resultantes de la difusión indiscriminada de plaguicidas y la pérdida de autonomía política. Porque éstos tienen relación con la práctica misma de la producción sojera bajo las formas que se da en Argentina y en el Cono Sur. Al respecto, vale subrayar que, en cualquier caso, la ignorancia u ocultamiento de estos procesos y sus impactos negativos es semejante, independientemente de su localización. Y precisamente lo que este trabajo pretende es evidenciar esta cuestión del ocultamiento, porque es a través del desconocimiento de hechos como los que aquí se describen que se sostiene la hegemonía del actual modelo de "desarrollo" desigual.

De todos modos y en cualquier caso, la ignorancia u ocultamiento de estos procesos y sus impactos negativos 
son semejantes independientemente de la respectiva localización. Y precisamente lo que este trabajo pretende es evidenciar, tener clara, esta cuestión del ocultamiento. Porque es a través del desconocimiento de hechos como los señalados que se sostiene la hegemonía del actual modelo desigual de "desarrollo".

Por ejemplo, se difunde y se piensa que los efectos negativos resultantes de las nuevas formas de acumulación del capital se circunscriben a un espacio determinado y afectan exclusivamente a la población localizada en el entorno de estos emprendimientos, lo cual se asocia con la falsa percepción de que, por tanto, podrían aislarse y prevenirse cuando, por el contrario, su alcance es extendido, difuso, global, y compromete a toda la sociedad.

La reprimarización de las economías del Cono Sur controlada directa o indirectamente por grandes corporaciones multinacionales (Monsanto, Syngenta, Bayer, Cresud, Cargill, ADM, Maggi, Bunge, entre otras) condiciona la soberanía nacional a través de la pérdida de la autonomía de la gestión política, económica y científica de los distintos países. De este modo, la democracia misma se torna incompatible con el control corporativo.

En el presente trabajo nos proponemos poner en discusión estos temas de la problemática territorial de las economías latinoamericanas, tomando como ejemplo fundamentalmente el caso argentino. Nos vamos a referir a hechos que afectan, en lo inmediato, la subsistencia de numerosas poblaciones que habitan y viven de los recursos que están en disputa (tierra, agua, bosques). Y observaremos que estas formas de acumulación extractivista y especulativa, características de la presente etapa del capitalismo a escala latinoamericana y mundial, comprometen el futuro de la sociedad en su conjunto.

\section{La expansión sojera en el Cono Sur latinoamericano}

La producción mundial de soja viene siendo liderada por Estados Unidos desde finales de la segunda guerra mundial. Hacia la década de 1960 comenzó a producirse soja en el sur latinoamericano, específicamente en Brasil (entonces bajo un gobierno militar). Fue en 1970 cuando se inició una expansión sostenida y acelerada de dicha producción, especialmente en Argentina y Brasil, lo cual implicó que en 2012 el Cono Sur superara la producción de Estados Unidos y de América del Norte. La Tabla 1 muestra que en 1972 Brasil concentraba casi toda la siembra y producción de Sudamérica (92\%) y Estados Unidos dominaba claramente en el mercado mundial de soja, controlando más del 70\% de dicha producción. Esta situación se fue modificando y en 2012 el Cono Sur, con el liderazgo conjunto de Brasil y Argentina, alcanzó la mitad de la producción mundial de soja, y comenzó a cuestionar el liderazgo de Estados Unidos como principal productor.

\begin{tabular}{|c|c|c|c|c|c|c|c|c|c|c|}
\hline \multirow{3}{*}{ PEGIONES/PÁISES } & \multicolumn{5}{|c|}{ ÁREASEMMBAAAA } & \multicolumn{5}{|c|}{ PRODUCCIÓN } \\
\hline & \multicolumn{2}{|l|}{1972} & \multicolumn{2}{|c|}{2012} & $\begin{array}{c}\text { TASA DE } \\
\text { CPECIMIENTO } \\
\text { ANUAL } \\
\text { ACUMULA TYA }\end{array}$ & \multicolumn{2}{|c|}{1972} & \multicolumn{2}{|c|}{2012} & $\begin{array}{c}\text { TASA DE } \\
\text { CRECIMIENTIO } \\
\text { ANUAL } \\
\text { ACUMULATIVA }\end{array}$ \\
\hline & $\mathrm{HA}$ & $\%$ & $\mathrm{HA}$ & $\%$ & $\%$ & $\mathbb{N}$ & $\%$ & $\mathbb{N}$ & $\%$ & $\%$ \\
\hline TOTALMUNDDAAL & 31.724286 & 100 & 104997.253 & 100 & $3.0 \%$ & 47.257.203 & 100 & $241.841,416$ & $100]$ & $42 \%$ \\
\hline ESTADOS UNMDOS & 18486.992 & 58 & $30,814,720$ & 20 & $13 \%$ & 34.580864 & 73 & 82790800 & 34 & $22 \%$ \\
\hline IOTALAMÉAICA DEL SUR & 2.394 .380 & 8 & 4.871.349 & 46 & $7,8 \%$ & 3.509 .27 & 7 & 119.896.953 & 50 & $9,2 \%$ \\
\hline IOTALCONOSUR & 2.337 .055 & & 4.649.104 & 45. & $3.8 \%$ & $3,400,131$ & & 115.068.124 & 48 & $9.2 \%$ \\
\hline ARGENTIINA & 68.000 & & 12572320 & 17 & $14.9 \%$ & 78.000 & & $40,100.197$ & 17 & $15,9 \%$ \\
\hline BOLVVIA & 800 & 0 & 1.222 .826 & 1 & $20,3 \%$ & 1.200 & 7 & 2.661 .910 & 1 & $2,2 \%$ \\
\hline BRASIL & 2.191 .455 & 7 & 24.975 .258 & 24 & $63 \%$ & 3.222 .631 & 7 & \begin{tabular}{|c|}
65.848 .85 \\
\end{tabular} & 27 & $7.8 \%$ \\
\hline PARAGLAYY & 75.000 & 证 & 2.920 .000 & 3 & $9,6 \%$ & 97.100 & & 4.344 .960 & 2 & $\underline{10,0 \%}$ \\
\hline URILGLUAV & 1000 & 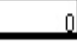 & $\$ 3.700$ & 1 & $18.5 \%$ & 1.200 & & $2,112,2000$ & 7 & $20.5 \%$ \\
\hline
\end{tabular}


Fueron 40 años durante los cuales Brasil y Argentina experimentaron un altísimo crecimiento con tasas que, en el caso de Brasil, duplicaron las mundiales (tanto en superficie sembrada como en producción). La expansión más notoria ocurrió en Argentina, con un crecimiento extraordinario en dicho periodo: tanto en el área sembrada, que quintuplicó los valores mundiales (15\% Argentina frente a 3\% mundial) como en volumen de producción (17\% Argentina y 4\% mundial -Tabla 1).

Y si bien también otros países de Sudamérica (como es el caso de Bolivia y Uruguay) tuvieron importantes crecimientos, aun a tasas mucho mayores, es asimismo cierto que partieron de magnitudes absolutas casi nulas. No es el caso de Argentina cuya participación llegó al 17\% de la superficie y de la producción mundial de soja en 2012, y se mantuvo en los años siguientes con cifras y rendimientos en continuado aumento, como surge de la tabla 2. Obsérvese asimismo que Argentina viene liderando en los dos últimos años el aumento de los rendimientos (9,7\%) incluso por encima de Estados Unidos (8,5\%).

\begin{tabular}{|c|c|c|c|c|c|c|c|c|c|c|c|}
\hline \multirow{3}{*}{ REGIONES/PAISES } & \multirow{2}{*}{\multicolumn{2}{|c|}{$\frac{\text { PRODUCCCIÓN }}{2013}$}} & \multicolumn{2}{|c|}{ AREA SEMIBRADA } & \multirow{3}{*}{$\begin{array}{c}\text { RENDIMIIENTOS } \\
2013 \\
\text { TN/HA } 11\} \\
\end{array}$} & \multicolumn{2}{|c|}{ PRODUCCCIÓN } & \multicolumn{2}{|c|}{ AREA SEMBBRADA } & \multirow{2}{*}{\begin{tabular}{|c|} 
RENDIMIIENTOS \\
2014 \\
\end{tabular}} & \multirow{2}{*}{ 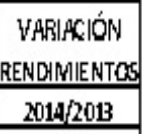 } \\
\hline & & & 2013 & & & 20 & & 2014 & & & \\
\hline & TN & \% & $\mathrm{HA}$ & * & & $\mathrm{TN}$ & $\%$ & HA & $\%$ & $T N / H A[1]$ & * \\
\hline TOTALMUNDIAL & $278,092,981$ & 100 & $111,630,495$ & 100 & 24 & $303,436,056$ & 100 & $117,718,624$ & 100 & 2,62 & 5,226 \\
\hline ESTADOS UNNIDOS & $91,389,350$ & 33 & 30.858 .830 & 28 & 20 & $100,013,660$ & 3 & $33,613,960$ & 20 & 3.21 & 8.58 \\
\hline TOTALAMMÉR|CADEELSUIR & 14,6,043,15] & 53 & $52,8.85,0.02$ & 4 & 27 & $15,7,20,040$ & 51 & $55,778,959$ & 8 & 2.81 & 1,72 \\
\hline TOTALCONOSLIR & 145.849.814 & 52 & 52.783 .389 & s & 27.7 & $155,51,060$ & 51 & $55,706,399$ & s & 2.81 & 1.72 \\
\hline ARGENTINA & $49,306,200$ & 18 & $29,418.824$ & 17 & 2 되 & $53,397,715$ & 17 & 19.252 .552 & 16 & 277 & 9.28 \\
\hline BOWWIA & 2968.137 & & 13228000 & 4 & 224 & $3.275,025$ & & 1.358 .68 & & 24.1 & 288 \\
\hline ARASIL & 81.724 .477 & 29 & $27,905,675$ & 25 & 29 & 86.760 .520 & 28 & 30.273 .763 & 26. & 287 & -2.18 \\
\hline PARAGUAY & 9.026 .000 & & 3.080 .000 & 3 & 29 & 9.975 .000 & & 3.500 .000 & & 2.85 & $-3,40$ \\
\hline URIKGIUAY & 2765,0000 & & 1050,000 & it & 28 & $3,162.800$ & & $1,321,400$ & & 233 & $-9,180$ \\
\hline ENTE: Elabor & gia a partird & & OSTAT 201 & & & & & & & & \\
\hline
\end{tabular}

Evidentemente, esta etapa de más de 4 décadas constituye, respecto a la soja, una verdadera explosión productiva (notoria en Argentina, pero también en el resto de los países productores del Cono Sur). La misma puede explicarse por diferentes cuestiones y medidas de carácter internacional y nacional.

En el ámbito internacional se sucedieron situaciones como: disminución de cosechas por parte de países productores (especialmente Estados Unidos); aumento de la demanda desde algunos importadores (la Unión Soviética primero y China después); aumentos de precios, acuerdos comerciales liderados por Estados Unidos para promover el acceso de la soja al mercado europeo; legislaciones restrictivas al comercio de granos; expansión de la producción de derivados, como los agrocombustibles (Coalición Holandesa de la Soya, 2008, pp. 15-17). Y a nivel nacional, en el caso de Argentina se suma a lo anterior la desregulación de la década de 1990. En particular, el decreto 2284 de 1991 que eliminó las juntas reguladoras (Junta Nacional de Granos, de Carnes, Dirección Nacional del Azúcar, etc.) y los sistemas de cuotas de producción y/o precios sostén de la actividad agropecuaria. Además, en esos mismos años se introdujo la soja transgénica y la siembra directa (en 1996 se produjo la liberalización de la soja transgénica). Los incrementos productivos se vieron impulsados, a su vez, por la suba de precios y de demanda. Es decir, se conformó un contexto productivo y económico muy favorable, en el que gobiernos y empresas agropecuarias (especialmente en Argentina y Brasil) se posicionaron para promover y ampliar el área y la producción de soja.

Todo esto se tradujo en significativas y complejas transformaciones territoriales, en los más variados sectores de la vida social y laboral. De hecho, un ejemplo útil para caracterizar este devenir es que, en el año 2003, la corporación Syngenta (empresa líder mundial en la producción de semillas) hizo una publicidad en la que define como la República Unida de la Soja a los territorios sojeros de Argentina, Brasil, Bolivia, Paraguay y 
Uruguay (Grain, 2013).

Este acelerado crecimiento no parece detenerse, en buena medida, porque la producción de soja continúa ligada -en el marco del Cono Sur latinoamericano- a la demanda de China, impulsada por el mayor consumo de sus sectores sociales medios.

\section{La expansión sojera en Argentina}

En Argentina hubo un regular crecimiento de la producción sojera en los últimos 40 años, en el que se incluyen los 12 años de los gobiernos de Néstor Kirchner y de Cristina Fernández de Kirchner (2003-2015). Precisamente, fue en estos años cuando el cultivo de soja se constituyó en el eje de la economía argentina, en tanto resulta ser su principal fuente de divisas.

Una causal significativa de esta expansión fue el boom de los precios de la soja de la primera década del $2000^{\underline{8}}$, sumada a la existencia de un favorable contexto nacional dado que la soja no es parte de la canasta alimentaria argentina (como sí lo es el trigo). Entonces, su comercialización en el mercado internacional no compite con el abastecimiento del mercado interno y su potencial suba de precios no afecta la canasta familiar de alimentos (como sí sucede con el trigo). En este sentido, la soja tiene la ventaja (respecto a otros productos agropecuarios, como trigo, maíz o carne) de superar la restricción externa propia de los productos que abastecen o se dirigen a ambos mercados (interno y externo).

Por todo esto, la comercialización internacional de la soja logró una expansión duradera y apuntaló las reservas internacionales, lo que posibilitó cancelar obligaciones con el exterior durante los gobiernos kirchneristas (Paez, 2016, p. 26).

Paéz (2016, p. 3) sostiene que desde principios del siglo XXI y sobre las bases de las transformaciones de las décadas anteriores:

...el cultivo de la soja adoptó un rol central en la economía argentina. Por un lado, el contexto de elevados precios internacionales y la adopción de un nuevo bloque tecnológico promovieron la siembra del cultivo en 15 de las 24 provincias. Durante la campaña 2013-2014, el cultivo alcanzó la cobertura de 20 millones de hectáreas sembradas, lo que implicó dos tercios de la superficie total sembrada en la Argentina. Estos simples números muestran la relevancia económica, territorial, política y social que ha adquirido la oleaginosa, ya no solo en la tradicional Pampa Húmeda sino también en zonas extrapampeanas.

La Tabla 3 rescata una serie anual sobre la expansión sojera desde el inicio de la década de 1980. En la misma se observa el aumento casi constante de la producción, superficie y rendimientos, con pocos retrocesos (dos notorios en 1989 y 2009 ligados ambos a crisis económicas nacionales, como la hiperinflación de fines de los años '80 y el conflicto del campo sucedido en 2008). Esta serie de 35 años muestra que la producción se multiplicó 35 veces y la superficie poco menos de 10; esto da cuenta del aumento de los rendimientos, especialmente durante el gobierno kirchnerista (asociado con los altos precios que los commodities obtuvieron en dicho período).

Todos los indicadores parecieran confirmar que esta expansión continuará durante los próximos años. Más aún porque con el gobierno de Mauricio Macri, iniciado el 10 de diciembre de 2015, se están modificando sustancialmente los patrones de referencia previos hacia una matriz claramente neoliberal, concentradora, desigual y conservadora en el campo económico, social y cultural, cuyas primeras medidas se dirigieron a impulsar al sector agropecuario a través de la liberalización del mercado cambiario, la quita o reducción de los aranceles a las exportaciones y la limitación de la legislación restrictiva en cuanto a la compra de tierras 
por inversores extranjeros.

En este marco, muy posiblemente la sojización avance a mayor ritmo, a menos que la desaceleración de la economía China -que desde 2015 algunos observadores mencionan- resulte muy pronunciada o que crisis climáticas o ambientales detengan las señales positivas que se observan para el mercado sojero argentino desde diciembre de 2015.

\begin{tabular}{|c|c|c|c|}
\hline \multicolumn{4}{|c|}{$\begin{array}{l}\text { TABLA 3: ARGENTINA, SOJA, PRODU } \propto I O ́ N, \text { ÁREA SEMBRADAY } \\
\text { RENDIMIENTOS.1980 - } 2014\end{array}$} \\
\hline \multirow[b]{2}{*}{ AÑos } & \multicolumn{3}{|c|}{ ÁREA SEMBRADA } \\
\hline & $\begin{array}{c}\text { PRODUCCIÓN } \\
\text { TN }\end{array}$ & $\begin{array}{c}\text { ÁREA SEMBRADA } \\
\text { HA }\end{array}$ & $\begin{array}{c}\text { RENDIMIENTO } \\
\text { TN/HA }\end{array}$ \\
\hline 1980 & 3.500 .000 & 2.030 .000 & 1,72 \\
\hline 1981 & 3.770 .000 & 1.880 .000 & 2,01 \\
\hline 1982 & 4.150 .000 & 1.985 .600 & 2,09 \\
\hline 1983 & 4.000 .000 & 2.280 .700 & 1,75 \\
\hline 1984 & 7.000 .000 & 2.910 .000 & 2,41 \\
\hline 1985 & 6.500 .000 & 3.269 .000 & 1,99 \\
\hline 1986 & 7.100 .000 & 3.316 .000 & 2,14 \\
\hline 1987 & 6.700 .000 & 3.532 .650 & 1,90 \\
\hline 1988 & 9.900 .000 & 4.373 .200 & 2,26 \\
\hline 1989 & 6.500 .000 & 3.931 .250 & 1,65 \\
\hline 1990 & 10.700 .000 & 4.961 .600 & 2,16 \\
\hline 1991 & 10.862 .000 & 4.774 .500 & 2,28 \\
\hline 1992 & 11.310 .000 & 4.935 .710 & 2,29 \\
\hline 1993 & 11.045 .400 & 5.116 .235 & 2,16 \\
\hline 1994 & 11.719 .900 & 5.748 .910 & 2,04 \\
\hline 1995 & 12.133 .000 & 5.934 .160 & 2,04 \\
\hline 1996 & 12.448 .200 & 5.913 .415 & 2,11 \\
\hline 1997 & 11.004 .890 & 6.393 .780 & 1,72 \\
\hline 1998 & 18.732 .172 & 6.954 .120 & 2,69 \\
\hline 1999 & 20.000 .000 & 8.180 .000 & 2,44 \\
\hline 2000 & 20.135 .800 & 8.637 .503 & 2,33 \\
\hline 2001 & 26.880 .852 & 10.400 .193 & 2,58 \\
\hline 2002 & 30.000 .000 & 11.405 .247 & 2,63 \\
\hline 2003 & 34.818 .552 & 12.419 .995 & 2,80 \\
\hline 2004 & 31.576 .752 & 14.304 .539 & 2,21 \\
\hline 2005 & 38.289 .744 & 14.032 .198 & 2,73 \\
\hline 2006 & 40.537 .364 & 15.130 .038 & 2,68 \\
\hline 2007 & 47.482 .784 & 15.981 .264 & 2,97 \\
\hline 2008 & 46.238 .087 & 16.387 .438 & 2,82 \\
\hline 2009 & 30.993 .379 & 16.771 .003 & 1,85 \\
\hline 2010 & 52.675 .464 & 18.130 .800 & 2,91 \\
\hline 2011 & 48.888 .536 & 18.764 .850 & 2,61 \\
\hline 2012 & 40.100 .196 & 17.577 .320 & 2,28 \\
\hline 2013 & 49.306 .200 & 19.418 .824 & 2,54 \\
\hline 2014 & 53.397 .715 & 19.252 .552 & 2,77 \\
\hline
\end{tabular}

En los hechos, la producción agropecuaria con eje en la soja no detuvo su crecimiento, aun cuando desde el 2008 se hizo evidente y más agudo un enfrentamiento (hasta entonces en parte latente) entre el sector agrario empresarial de mayores recursos y el gobierno de Cristina Kirchner $\underline{9}$. Fue lo que se denominó conflicto del campo, provocado por la política de aumento de los aranceles a la exportación de productos agropecuarios, en particular a la soja, la cual no pudo efectivizarse en los términos planteados.

Esta conflictividad desaparece bajo el gobierno de M. Macri, claramente aliado al sector agropecuario que lideró aquel frente agrario opositor al gobierno de Cristina Kirchner. Esta alianza se tornó evidente con una de las primeras medidas del gobierno macrista: a tan sólo 4 días de su asunción se eliminaron los derechos de exportación de los productos agropecuarios. Para la soja se los disminuyó un 5\% (pasó del 35\% al 30\% y del $32 \%$ al 27\% para los respectivos derivados) y se instrumentó un plan anual de baja de dichos derechos $\underline{10}$. 
Pero a lo anterior se sumó pocos días después (el 16 de diciembre) la liberalización del cepo a la compra de dólares y la apertura del mercado cambiario. Esto significó una devaluación de más del $40 \%$ del peso argentino. O sea, simultáneamente se tomaron dos medidas directamente ligadas a beneficiar y promover al sector agroexportador y expandir aún más la producción sojera. $\underline{11}$

Se trata de decisiones y acciones con significativas consecuencias territoriales que conllevan enormes daños colaterales: mayor deforestación; expansión del uso de plaguicidas, herbicidas, semillas transgénicas; dependencia de las transnacionales de la agroindustria y de las proveedoras de semillas y otros insumos; expulsión y persecución de la población rural de menores recursos.

Como es evidente, estas medidas profundizan el fortalecimiento de la cadena agroindustrial (productores, comercializadores y exportadores de granos, y sectores conexos: semillas, aceites, fertilizantes, agroquímicos, maquinarias, innovación y tecnología, finanzas), ya que consolidan y aumentan los procesos de acumulación y de concentración económica agroindustrial, alimentaria y financiera.

En una segunda instancia, la expansión productiva y las transformaciones territoriales se traducen en procesos regresivos de carácter social, ambiental y cultural, y a su vez en el fortalecimiento de un renovado campo de poder (un poder hegemónico conformado por antiguos y nuevos actores relacionados al sector agroindustrial y alimentario, al financiero y a los medios masivos de comunicación). Además, se debilitan sectores sociales conformados por trabajadores, pequeños y medianos productores agropecuarios, productores familiares, empresarios y pequeñas y medianas empresas industriales, comerciales, de servicios, cooperativistas, desocupados. A ellos se suman también los integrantes de distintos movimientos sociales vinculados con los derechos humanos -de género, de diversidad étnica y sexual- y con las poblaciones originarias (Grain, 2013; REDAF, 2010).

En Argentina, las expectativas y el impulso al crecimiento de la producción de soja estaban claramente presentes desde la gestión de gobierno de Cristina Kirchner. Entonces, desde el Ministerio de Agricultura se gestó el Plan Estratégico Agroalimentario y Agroindustrial, Participativo y Federal -PEA- 2020, que proponía como meta para el 2020 una superficie sembrada de 22 millones de hectáreas y una producción de 71 millones de toneladas de soja. $\underline{12}$ Esta proyección fue yendo por buen camino, ya que, a diciembre 2015, la superficie sembrada de soja superaba los 20 millones de hectáreas, lo que constituía un nuevo hito de crecimiento $\underline{13}$.

Se trata de una expansión con múltiples significados e interpretaciones. Por un lado, aumenta notoriamente el volumen exportable de soja, lo que atrae divisas para la economía nacional -tema central para todo gobierno-; pero, por otro, podría debilitar aún más el control del mercado de granos y oleaginosas por parte del estado argentino, porque la concentrada estructura agroindustrial y exportadora seguirá su derrotero excluyente y, consecuentemente, incrementará su poder en el campo de las decisiones políticas. A esto se suma un nuevo y particular actor: las inversiones de origen semiestatal de China dirigidas a la producción, comercialización y exportación de soja para venderla a su propio mercado de consumo. Al respecto, es notorio el aumento acelerado de estas inversiones en la región (expresadas en la adquisición del 51\% de las acciones de Nidera Argentina) $\stackrel{14}{\underline{14}}$. Cuestión paradójica, porque mientras desde el poder político, los medios hegemónicos de comunicación y, en general, los discursos políticos se plantea la enorme oportunidad que representa para Argentina y todo el Cono Sur vender soja a China. Se ignora o se oculta que son capitales semiestatales chinos los que en realidad hacen el negocio, pues invierten y producen en países del Cono Sur lo que luego se venderán a sí mismos para abastecer su propia demanda de alimentos. Se trata de un proceso de acumulación ampliado y de expansión territorial controlado y garantizado en su devenir completo por y para el capital chino. 


\section{Transformaciones del territorio: más allá de las leyes y el derecho}

Dada la conflictiva situación ambiental y social del presente (que iremos retratando en los párrafos que siguen) consideramos que aumentos en torno o superiores al 20\% de la superficie sembrada y al $35 \%$ de la producción (como los proyectados y los que se vienen dando en relación a la soja) profundizarán los procesos: (i) de despojo y desposesión de la población criolla y originaria, (ii) de deforestación y pérdida de biodiversidad, (iii) de judicialización y represión de la protesta social, (iv) de contaminación ambiental por el creciente uso de agroquímicos.

Metas de ese orden de magnitud constituyen una apuesta de alto riesgo, que compromete el futuro social y ambiental de Argentina, así como la estabilidad político-institucional y la democracia misma (tan sólo por el aumento de la desigualdad social y la concentración económica que estos procesos ya han producido y cuyo acrecentamiento se proyecta hacia el futuro).

Desde luego, esto trasciende a Argentina y al Cono Sur. El extractivismo y la reprimarización tienen que ver con "una fiebre global por la tierra, por la minería y por los recursos naturales en general”, como sostiene Paulo Tavares (Ñ Clarín, 18-6-2013) ${ }^{15}$, lo cual nos ha llevado a que el cambio climático -desde el año 2000 - se torne un proceso irreversible, originado por una concepción en la que la naturaleza es un objeto de apropiación, de propiedad:

...repensar esto es un cambio radical porque significa mudar sistemas legales, organizativos, institucionales. Significa repensar formas culturales de relacionarse con el otro que es la naturaleza, pero también repensar paradigmas científicos. Los desafíos son entonces múltiples, porque tocan nuestro propio modo de ver el mundo, la cosmología occidental.

Tavares sostiene que se necesita discutir acerca de los derechos de la naturaleza; lo que propone es una transformación cultural y simbólica de carácter contrahegemónico, porque el cambio que se postula atañe al campo de la cultura, instituida y constituida a través de los valores y a lo largo de la historia para construir y fortalecer la hegemonía.

En este contexto, pareciera que sólo atravesando crisis sociales, económicas, ambientales, con sus profundos y complejos conflictos y disputas podrá proyectarse una cultura contrahegemónica. Es decir, es muy difícil confiar en modificaciones o nuevos diseños del campo legal, organizativo e institucional del sistema actual (en el que se sustenta la hegemonía) que permitan una transformación cultural respecto a los "derechos de la naturaleza”. Hay aquí un ámbito de disputa de la hegemonía que no debería soslayarse, porque implica crisis de enorme magnitud.

La sojización expresa procesos de amplitud y manifestación a escala global. Sus transformaciones territoriales son innumerables y contundentes, y, en varios sentidos, inabarcables para cualquier sistematización y/o descripción (aunque se tratara de un sólo caso de estudio circunscripto espacialmente). Sus connotaciones materiales y simbólicas resisten toda delimitación metodológica.

Las metamorfosis territoriales asociadas con la sojización en el Cono Sur latinoamericano trascienden a esta región; aparecen en otras geografías y territorios, no sólo en los vinculados directamente con la producción de soja. Para dimensionar sus alcances habría que identificar desde cada territorio la cadena que lo conecta con los productores de insumos y maquinarias, los empresarios del sector, los especuladores que persiguen ganancias extraordinarias, los organismos de ciencia y técnica que producen innovaciones, los medios de comunicación masivos que avalan y sostienen el avance de los agronegocios, los consumidores que seleccionan sus productos y derivados. Y, del mismo modo, importa reconocer a los actores y procesos que resisten su difusión, desde las organizaciones de productores, ambientalistas, comunidades originarias, hasta las instituciones públicas y privadas y la población que se opone a este avance desenfrenado sobre la sociedad y su ambiente. 
En las más de 55 millones de hectáreas cultivadas con soja (Tabla 2) del Cono Sur en 2014, quienes controlan y operan estos procesos lo hacen a través de similares modalidades. En la mayor parte de esta superficie predomina el monocultivo de soja transgénica; se fumiga con glifosato y se deforesta para ampliar la superficie cultivable. Grain (2013) calcula que, en 2012, en el Cono Sur se aplicaban 600 millones de litros de glifosato y que la deforestación, como mínimo, alcanzaba 500 mil ha por año. En el caso argentino, la Secretaría de Medio Ambiente y Desarrollo Sustentable de la Nación (2012, pp. 95, 97) corrobora esta afirmación al referirse a la constante pérdida de superficie de bosque nativo, acelerada en las últimas décadas: "la deforestación para el período 1998-2002 es de aproximadamente 230.000 hectáreas/año, mientras que en el período 2002-2006 se perdieron 330.000 hectáreas/año de bosques nativos”.

Los grupos que lideran y conducen el extractivismo y la reprimarización de la economía de Sudamérica pueden ser identificados, son pocos y poderosos y, como dice Grain (2013), tienen nombre y apellido: "Monsanto y algunas corporaciones biotecnológicas más a la cabeza (Syngenta, Bayer); terratenientes y pooles de siembra que controlan millones de hectáreas (Los Grobo, CRESUD, El Tejar, Maggi son algunos de los principales); Cargill, ADM y Bunge transportando los granos”. A ellos deben agregarse las empresas proveedoras de insumos y servicios y los respectivos gobiernos nacionales, provinciales y locales aliados en este paradigma productivista.

Se trata de un proceso de continuado fortalecimiento del poder económico y político de unas pocas empresas y, simultáneamente, de debilitamiento del accionar de los estados en el ejercicio de su soberanía política.

La concentración en ámbitos clave de la economía es una realidad latinoamericana y mundial. Así sucede en Argentina con el sector exportador de granos en torno al cual gira toda la economía nacional. Es llamativo que Mario Llambías (un referente del agro, expresidente de Confederaciones Rurales Argentinas -CRA-, una de las 3 más importantes entidades representativas de los grandes productores rurales del país) haya manifestado en enero de 2011: "Hace siete años había 40 exportadoras, y hoy sólo 7 exportan el 90 por

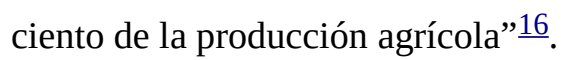

Estas 7 empresas son: Cargill, Aceitera General Deheza, Bunge, Molinos Río de la Plata, Vicentin, Louis Dreyfus Commodities y Asociación de Cooperativas Argentinas (ACA). Y son sólo otras pocas más las que operan con peso en el mercado exportador de cereales (Nidera, Noble, Oleaginosa Moreno, Los Grobo, Glencore, Adeco y ADM).

Este dato no puede corroborarse con cifras oficiales porque en 2008 el Gobierno nacional dejó de publicar las estadísticas sobre compras, ventas y embarques de granos (situación que se relaciona con el conocido “conflicto del campo" entre el gobierno y los productores agropecuarios por la aplicación de los derechos de exportaciones). Contar con dicha información permitiría comprobar el altísimo grado de concentración comercial de las multinacionales exportadoras y su acelerado aumento durante el período correspondiente al gobierno de Néstor Kirchner y de Cristina F. de Kirchner $\underline{17}$.

Pero dentro de estas transformaciones territoriales, en su mayor parte regresivas socialmente, hay una cuestión de enorme gravedad asociada a los agronegocios: en el Cono Sur oponerse a los agronegocios significa riesgo de vida. Diversos asesinatos están relacionados con resistencias sociales al avance depredador de los agronegocios.

En Argentina, el Movimiento Campesino de Santiago del Estero (Mocase-Vía Campesina) regularmente denuncia hechos de represión directamente relacionados con el avance de los agronegocios sobre territorios comunitarios. Un caso emblemático de resistencia es el de Cristian Ferreyra, un joven de 23 años perteneciente a la comunidad indígena Lule-Vilela (comunidad de dos mil hectáreas en San Antonio, Santiago del Estero). Cristian fue asesinado por dos encapuchados cuando intentó resistir un desalojo en el 
campo donde vivió toda su vida: "Esto es el Lejano Oeste, no se cumplen nuestros derechos, nos matan como animales”, denunció Marilena Santillán, compañera de militancia de Ferreyra e integrante del MocaseVía Campesina. En aquella oportunidad también fue herido Darío Godoy, de 26 años (Página 12, 18-112011). Darío Aranda, periodista especializado en temas rurales y uno de los pocos que denuncian estos crímenes ligados al avance de la soja, lo relata de este modo:

El miércoles, a la hora de la siesta, según contó ayer Julián Roqué, un compañero de la víctima, llegaron hasta la casa de Darío Godoy dos personas encapuchadas. Eran los hermanos Javier y Anton Juárez, dos guardias privados enviados por el empresarios santafesino José Ciccioli aseguró Roqué (...) Desde el Mocase denunciaron que los homicidas trabajan para un empresario agropecuario de la zona. (...) El Mocase-VC emitió un comunicado: Esto ocurre con complicidad y alevosía de parte de autoridades provinciales y funcionarios del Poder Judicial e instituciones como la Dirección Provincial de Bosques, que autorizó desmonte en un lugar donde viven familias campesinas indígenas de varias generaciones. A todos ellos los hacemos responsables directos del asesinato de Cristian (Página 12, 18-11-2011).

El mismo diario informa de otros homicidios de militantes, muertos en defensa de su territorio, previos al caso de Cristian: el diaguita Javier Chocobar en Tucumán el 12 de octubre de 2009; la campesina santiagueña Sandra "Ely” Juárez, que sufre un paro cardiaco frente a una topadora el 13 de marzo de 2010; el qom de Formosa Roberto López el 23 de noviembre de 2010 en un corte de ruta.

Se trata de una lucha muy desigual, en la que sectores de poder (político, económico y mediático) ocultan estos crímenes y protegen a sus autores materiales e intelectuales. El hecho que grupos empresarios violen el cumplimiento de las leyes, atenten contra los derechos consagrados en la constitución y lleguen hasta el homicidio indica, necesariamente, complicidad del estado (sea local, provincial o nacional).

Es sabido que estos crímenes no se investigan y sus autores materiales e intelectuales no son debidamente procesados y encarcelados. En el caso de Cristian Ferreira, que logró una mayor notoriedad, la sentencia de la Cámara del Crimen absolvió a Jorge Ciccioli, empresario señalado como autor intelectual, luego de un juicio oral realizado en Monte Quemado, a 220 kilómetros al norte de la capital provincial (Pagina 12, 2-22015). Entonces cabe preguntarse: ¿Quiénes son los responsables de que una sucesión de asesinatos no se esclarezca? ¿Por qué no se dilucida la trama de intereses comprometida con estos hechos? Todo indica protección a sectores poderosos vinculados con prácticas territoriales ligadas con la deforestación, el avance de la frontera agropecuaria y la ocupación de tierras para destinar a la expansión y monocultivo sojero, especialmente.

Nada revela que estas persecuciones, despojos y asesinatos vayan a terminar si tenemos en cuenta la dependencia de la matriz productiva argentina de la producción sojera y su muy probable continuidad y expansión productiva en los años venideros.

La ampliación de la frontera agraria (con sus consecuentes procesos de deforestación, desertificación, pérdida de la biodiversidad) significa, conjuntamente, la agudización de la conflictividad social, la cual empieza por los sectores directamente afectados.

Todos son temas y contradicciones del modelo sojero que no se conocen masivamente porque no se difunden en ciudades y grandes urbes. Del mismo modo, muy limitada ha sido la difusión de un estudio sobre conflictos de tenencia de la tierra y ambientales que contabilizó 259 conflictos sólo para la región del Chaco argentino en agosto de 2010 (REDAF, 2010:23).

Paraguay es otro ejemplo aún más desmesurado. Pues aquí se considera que el poder de los agronegocios ha llegado hasta a provocar la destitución del gobierno democrático del presidente Lugo. Paraguay ha estado 
siempre gobernado por el partido conservador Colorado con la sola excepción del período del gobierno de Lugo entre 2008 y 2012. Partido que ha avalado y profundizado con sus políticas una de las peores distribuciones de la tierra de América Latina: "El 80\% de la tierra cultivable (...) está en manos del 2\% de los propietarios, según cifras oficiales”토.

Esta situación y el acercamiento que se fue dando entre el gobierno de Lugo y sectores campesinos parecieran explicar la durísima oposición que se gestó motorizada por grupos nacionales aliados al agronegocio (Unión de Gremios de la Producción -UGP) y desde corporaciones internacionales (como Monsanto, Cargill).

Desde algunas áreas del gobierno de Lugo (Ministerio de Salud, Ministerio de Medio Ambiente, Servicio Nacional de Calidad y Sanidad Vegetal y de Semillas) se mantuvo un diálogo con las organizaciones campesinas que buscaba frenar las fumigaciones, los nuevos transgénicos y la ley de semillas. Esto devino en un ambiente político-institucional convulsionado, que se extremó con la matanza de Curuguaty (11 campesinos y 6 policías muertos el 15-6-2012). Esta se constituyó inmediatamente en el argumento que avaló el juicio político que terminó con la presidencia de Lugo (en un rapidísimo procedimiento concretado en menos de dos horas de sesiones parlamentarias. Grain, 2013).

Pero además lo sucedido en Curuguaty no fue investigado. Hay dirigentes locales que consideran que se trató de una conspiración contra el gobierno de Lugo $\underline{19}$, la cual, por su parte, se asocia y fundamenta en la ola represiva que se desató posteriormente y que terminó con la vida de 3 dirigentes de organizaciones campesinas. Este hecho fue calificado como un plan de exterminio, de asesinato selectivo de líderes campesinos $\underline{20}$. Esta misma apreciación surge del informe de la Coordinadora de Derechos Humanos del Paraguay del 10-12-2012, donde se afirma: “Curuguaty fue el nombre como la prensa denominó al conflicto que dio inicio a la crisis política más importante de los últimos 20 años de historia paraguaya. Curuguaty es sinónimo de estremecimiento político, pues costó 17 muertos y la caída de un gobierno legítimo”ㄹ⒈

También Paulo Tavares (Ñ, Clarín, 18-6-2013) vincula el golpe institucional al gobierno de Lugo con el avance de la soja y la centralidad de la problemática de la tierra en toda América Latina: "Ese golpe se dio por una cuestión que ha sido la cuestión fundamental para casi todos los golpes de estado que América Latina vivió durante mucho tiempo. Es la cuestión de la tierra.”

No hay duda que, en Latinoamérica, la tierra ha sido y sigue siendo central en la disputa de poder. Y en esta confrontación siempre ha predominado la presencia política de los sectores más conservadores de cada país.

\section{Transformaciones del territorio: construcción de hegemonía y marginalidad}

El tipo de desarrollo de las últimas décadas en el Cono Sur ha conducido al fortalecimiento de grupos de poder y de espacios y lugares desde donde se ejerce la dominación -como centros financieros y zonas de alto consumo de grandes ciudades-. Paralelamente se observa la debilidad y la marginación de otros ámbitos espaciales (afectados por la desertificación, la pérdida de la biodiversidad), y también de amplios sectores sociales.

Se trata de un modelo excluyente y concentrador que abandona a su suerte ("por los designios del mercado" dirían las corrientes del mainstream) a pequeños productores agropecuarios y de servicios: agricultores familiares, población originaria, trabajadores rurales. Muchos son habitantes de zonas deforestadas, o son desalojados y/o despojados de sus tierras y viviendas, o deben abandonar sus actividades, o son trabajadores de la salud, de la educación, de servicios, o familias y niños en edad escolar que deben enfrentar enfermedades producidas por la contaminación, la pobreza, la marginalidad; o conforman la población de pueblos y localidades cuyas principales actividades han quedado relegadas. 
En todos estos procesos está presente la profunda desigualdad que desencadena este modelo productivo de exclusión, del cual podemos identificar muchas transformaciones territoriales, mientras que otras continuarán siendo ignoradas en tanto puedan mantenerse ocultas. Enfermedades, plagas y hambre se suceden invisibilizadas por la trama de poder dominante, asociadas con los agroquímicos y con la pérdida de la biodiversidad. Se trata de procesos que afectan a los sectores más postergados, a los que viven en torno a los lugares de fumigación pero no únicamente a ellos, porque los agroquímicos se esparcen y difunden más allá del ámbito donde fueron aplicados y contaminan otros ambientes además de los alimentos que consumimos. En distintos tiempos y lugares, su nocividad alcanza a toda la población.

Las transformaciones territoriales más evidentes están asociadas directamente con la puesta en marcha, ampliación y mantenimiento de la cadena de producción y comercialización de la soja $\underline{22}$. Muchas son fácilmente identificables y en un primer acercamiento suelen evaluarse positivamente por la mayor dinámica económica y comercial que imprimen a ciertas localidades y por los signos de modernidad resultantes (como sucede con ciudades-puerto, como Rosario y Santa Fe, en Argentina).

La magnitud y complejidad de esta producción del territorio, asociada con el acondicionamiento de infraestructura requerida para la expansión de la producción y comercialización de la soja, puede ejemplificarse con un caso paradigmático: la Hidrovía Paraguay-Paraná, obra que comprende toda la cuenca del Rio de la Plata, la circulación de sus principales tributarios (los ríos Paraná, Paraguay y Uruguay) e involucra a buena parte de los países del cono sur latinoamericano (Argentina, Bolivia, Brasil, Paraguay y Uruguay). Esta monumental obra se enmarca dentro de la Iniciativa para la Integración de la Infraestructura Regional Suramericana (IIRSA), es promovida por la UNASUR (Unión de Naciones Suramericanas) y financiada por el Banco Interamericano de Desarrollo (BID) y bancos de desarrollo nacionales y regionales $\underline{23}$.

Además, en ciudades medias y grandes, la sojización contribuye a profundizar la polarización urbana, pues tanto ayuda a fortalecer la imagen de modernidad y pujanza como agudiza la marginalidad y exclusión social. De este modo se construyen ciudades polarizadas con claras y precisas imágenes de riqueza y de miseria, de inclusión y de exclusión, donde la desigualdad es la premisa y el proceso de sojización uno de sus desencadenantes $\underline{\underline{24}}$.

Las villas miserias constituyen una opción de residencia para muchas familias e hijos de pequeños productores y trabajadores rurales que quedan sin trabajo y desplazados de sus campos y viviendas a causa de la expansión sojera en el norte argentino, Paraguay y Bolivia. Al respecto, el ex secretario de Agricultura Familiar, Emilio Pérsico, dirigente del Movimiento Evita y conocedor de la situación de las villas (por su militancia en el movimiento de desocupados) sostenía: "los pibes que no trabajan ni estudian en las villas del conurbano bonaerense, los ni ni, son hijos de una campesina de Santiago del Estero”르.

Es decir, en general nos estamos refiriendo a transformaciones territoriales que son producto de procesos sociales y económicos que se dan a lo largo de décadas y que la sojización profundiza, si bien pueden haberse iniciado bastante antes. En su mayoría con consecuencias regresivas para el territorio y su población, por su menor diversificación productiva y mayor concentración económica. Así, en la década de 1990 se acelera fuertemente el proceso de concentración de la tierra, se intensifica la actividad agrícola en la pampa húmeda $\frac{26}{y}$ en las regiones extrapampeanas (noroeste y noreste). Es el caso de la agriculturización $\frac{27}{2}$ que se inicia a hacia la década de 1970 y que se consolida con la creciente expansión de la soja (Manuel-Navarrete et al; 2005, p. 8). 


\section{Bosques naturales amenazados por desertificación y pérdida de biodiversidad}

La deforestación de los bosques naturales trae consigo la pérdida de biodiversidad, la expulsión de la población local y originaria y conflictos y procesos ligados a varios de los hechos ya mencionados anteriormente (enfermedades, desalojos, judicialización, migración, marginalidad, precariedad).

El principal desencadenante de la deforestación que actualmente se da en Argentina es el avance de la frontera agrícola y ganadera hacia el centro y el norte del país, hacia el Gran Chaco $\underline{28}$, y llega hasta Paraguay y Bolivia.

En conmemoración del Año internacional de los Bosques, 2011, Eduardo Rojas Briales, responsable del tema bosques de la FAO, sostuvo que "el caso de Argentina es un punto neurálgico a nivel mundial debido a la pérdida de sus bosques”. Y Hernan Giardini, coordinador de la campaña de biodiversidad de Greenpeace de Argentina decía:

Los bosques de Argentina se encuentran desde hace unos 15 años en una situación de emergencia (...) Argentina perdió el 70 por ciento de sus bosques nativos originales. Hoy tiene 31 millones de hectáreas. En los últimos 10 años perdimos 2,5 millones de hectáreas a mano fundamentalmente de la soja transgénica y posteriormente la ganadería. $\underline{29}$

Según un informe de la Dirección de Bosques de la Secretaría de Ambiente y Desarrollo, en 1935 se realizó un censo forestal que calculó que la superficie total de bosques naturales era cercana a $1.100 .000 \mathrm{~km}^{2}$ (casi 40\% de la superficie nacional); en 2004 esa superficie se había reducido a $331.000 \mathrm{~km}^{2}$ (menos del 12\% de la superficie nacional $)^{\underline{30}}$.

Desde luego que una parte de esta pérdida forestal comenzó mucho antes de la expansión sojera $\frac{31}{\text {; }}$ y también antes de la pampeanización (expansión de las prácticas productivas y tecnologías de la pampa húmeda hacia regiones -como el semiárido, el norte y el chaco- con otras características ecológicas) ${ }^{32}$.

Pero con la soja y los bosques implantados la deforestación siguió avanzando cada vez en forma más acelerada. La Secretaria de Ambiente y Desarrollo Sustentable de la Nación (2012, pp. 95, 97) especifica que las zonas más afectadas por el reemplazo de grandes extensiones de bosque nativo por cultivos agrícolas son "las regiones Parque Chaqueño, Selva Misionera y Selva Tucumano Boliviana”. Conjuntamente, ha aumentado la superficie de plantaciones forestales, principalmente en las provincias de Entre Ríos, Corrientes y Misiones. Esta situación ha puesto en riesgo la sustentabilidad, especialmente en el noroeste y noreste argentino, como puede verse en el caso de la selva misionera cuyo bosque nativo era en 2002-2006 de 1.160.000 ha, en la selva tucumano-boliviana de 3.650.000 ha y en el parque chaqueño de 20.600.000 ha $\underline{33}$.

El parque chaqueño, donde fue notoria la expansión de la soja, es el más extendido y también el más depredado (a una tasa de pérdida de $1.44 \%$ anual entre 2002-2006) ㄴ $^{34}$. Sus suelos son naturalmente pobres en materia orgánica y afrontan un mayor riesgo climático, económico y ambiental (Secretaria de Ambiente y Desarrollo Sustentable de la Nación; 2012, p. 98).

Estos procesos de pampeanización hacia el semiárido chaqueño se caracterizan por un avance de la frontera agrícola y de las prácticas de la pampa húmeda hacia regiones de mayor fragilidad (en relación con la pampa húmeda). Algunas de sus consecuencias negativas, especialmente las relacionadas con el futuro productivo de las regiones del Gran Chaco, son difundidas por medios periodísticos (como los diarios La Nación y Clarín), lo cual pareciera contradecirse con el tradicional apoyo y defensa de la expansión productiva y de la agriculturización que vienen sosteniendo estos diarios $\frac{35}{5}$. Es el caso de una nota periodística de la edición 
impresa del suplemento Campo de La Nación del 2 de noviembre de 2013 con el sugerente subtítulo "La búsqueda de una renta rápida y la falta de un ordenamiento territorial exponen la región a las consecuencias de la sequía” $\underline{36}$. En la misma, tres expertos investigadores mencionan que el auge de la sojización en las zonas semiáridas y subhúmedas del noroeste y noreste argentino tiene varias causas $\underline{37}$. Entre ellas, mencionan: a) la presencia de un ciclo húmedo que se extendió por un cuarto de siglo y que estaría llegando a su fin en el siglo XXI, y b) "una coyuntura de valores elevados para los granos, en particular para la soja, con una generosa oferta de tierras a bajos precios...”.

Sin embargo, enfatizan que los resultados de esta expansión se traducen en ecosistemas seriamente afectados como "el bosque de tres quebrachos en Santiago del Estero, y la zona de transición Chaco-Yungas, en Salta" producto de que: (i) un 80 \% de las áreas transformadas eran bosques; (ii) se pasó de casi 5 millones de ha cultivadas en la región chaqueña entre 1995/1996 a 11,4 millones de ha en 2012; (iii) se potenció la susceptibilidad a la erosión hídrica y los procesos erosivos eólicos (que no eran de importancia cuando existía el bosque); y, finalmente (iv) la expansión de la frontera agrícola en la región chaqueña no respondió a un programa de ordenamiento territorial sino, claramente, a las leyes del mercado, ya que para estos ambientes no se recomienda ni el desmonte masivo, ni el monocultivo de soja (La Nación, 2-11-2013).

\section{Producción del territorio y poder: bajo la reprimarización de la economía latinoamericana}

Comenzamos esta reflexión con una cita de Moraes (2005, p. 15) que encuadra nuestra perspectiva de análisis respecto a las situaciones que luego expondremos:

Todos sabemos que las formas espaciales son productos históricos. El espacio producido es un resultado de la acción humana sobre la superficie terrestre que expresa, a cada momento, las relaciones sociales que le dieron origen. En este sentido, el paisaje manifiesta la historicidad del desarrollo humano, asociando objetos fijados al suelo y genéticamente fechados (traducción nuestra).

Estas relaciones sociales son relaciones de poder y como tales aparecen y se expresan a través de numerosas acciones que van transformando el territorio. Se trata de una producción social del espacio que en muchos aspectos se torna imperceptible para nuestro mirar cotidiano.

Precisamente, en el presente, con el modelo extractivista y de reprimarización de las economías latinoamericanas se están gestando escenarios territoriales, opresivos y desbastadores que se repiten y difunden sin obtener mayor difusión pública. Despojo de los recursos, avasallamiento y persecución de la población, y judicialización de la protesta social son modos de sometimiento cada vez más extendidos que, además, cuentan con avales institucionales en beneficio de poderosos intereses locales y extralocales (económicos, financieros, políticos, judiciales).

Comunidades originarias, pequeños productores, campesinos, agricultura familiar $-\mathrm{AF}-\frac{38}{}$, cada una con sus particularidades -territoriales, productivas, tecnológicas, sociales- se enfrentan al hambre, a la migración forzada, a la difusión de enfermedades resultantes de la contaminación del agua y de las variadas fumigaciones con agrotóxicos (especialmente entre niños, embarazadas y ancianos), a la destrucción de puestos y fuentes de trabajo, a la deforestación, a la depredación de suelos, a la pérdida de la biodiversidad $\underline{39}$.

Se trata de procesos que buscan aislar -sino hacer desaparecer- a estas poblaciones condicionando sus formas de reproducción y desacreditando sus identidades, culturas, modos de vida, formas de interacción social. Un ejemplo cabal de este pensamiento degradante y estigmatizante aparece en la opinión pública de uno de los principales referentes del poder empresarial que lideró la transformación territorial de los últimos 25 años de Argentina, Eduardo Leguizamón, ex presidente de Nidera Argentina $\frac{40}{}$, quien afirma, entre 
muchos otros desatinos, que "El monte nativo no es algo romántico: por el contrario, es algo siniestro. En él habitan seres humanos que están más cerca de la escala animal que de la humana” (La Nación, suplemento Campo, 21-08-2004). Se trata de un relato obsceno que muestra una ajustada expresión de ejercicio de poder a través de un discurso conservador que, con argumentos eficientistas, busca habilitar el acceso del capital a nuevas tierras (Naharro, Alvarez, y Klarik, 2009, p. 145).

Al aplicar exclusivamente la cosmovisión occidental y un tono claramente despreciativo y discriminatorio de otras formas de vida, de otras identidades, se desconoce, omite o manipula la realidad. Se ignora que, junto con la globalización, se configura una sociedad cada vez más multicultural; que junto con las formas capitalistas de consumo se visibilizan otras identidades y prácticas sociales y culturales, frecuentemente ocultadas; que han aumentado las interacciones de mercado, de consumo capitalista pero también los intercambios y vivencias entre variadas y diferentes culturas.

Esta cerrada y eurocéntrica percepción social menosprecia y agravia a la población criolla del monte y a las comunidades originarias, injuria y tergiversa sus formas de vida, desconoce o enmascara sus derechos constitucionales sobre la tierra (ocupada ancestralmente por los antepasados de las comunidades actuales), y engaña acerca de las oportunidades de empleo que tendrían quienes abandonaren sus tierras $\underline{41}$.

La realidad territorial nos muestra que no habrá oportunidades de empleo para la población desplazada, porque la demanda asociada a las nuevas producciones agroindustriales es menor, selectiva y especializada; en otras palabras, es de acceso nulo para los pequeños productores y población originaria. Si la población desplazada sobreviviera a todos los procesos conexos que la esperan a partir de la expulsión de su hábitat terminaría, en el mejor de los casos, engrosando la población de las villas miserias. Es decir, literalmente en la miseria y, en general, en las márgenes de las grandes urbes o ciudades medias. Y éstas son una parte, no menor, de las transformaciones territoriales resultantes de la sojización.

Las ideas y discursos como los expresados por el ex presidente de Nidera producen consecuencias, hechos de dominación a través de los valores que transmiten y de las acciones y políticas que promueven.

Es de este modo como se construyen y configuran barreras de exclusión territorial que operan en el campo de la ideología, de la práctica, y definitivamente en el de la construcción de hegemonía $\underline{42}$. Más allá de su verosimilitud o racionalidad, resultan difíciles de franquear, porque conforman mitos, tradiciones, creencias, cosmovisiones, valores, que integran y alimentan el discurso de poder hegemónico, y, como tales, avalan el funcionamiento del sistema capitalista en sus diferentes expresiones escalares.

En otras palabras, conforman la cultura de una sociedad que -como sostiene Portes (2006, p. 22)- es "donde se incorporan los elementos simbólicos, la esfera de los valores de la sociedad, los marcos cognitivos y del conocimiento acumulado". Y es en este campo donde "las elites que controlan los recursos que confieren poder tratan de estabilizar y perpetuar su posición”, moldeando creencias para que "la masa de la población sea persuadida de la 'justicia' del orden existente”. Entonces, consolidar posiciones de poder exige instituciones que trasciendan a las personas y, más allá de ellas mismas, respondan a los valores que conforman la estructura social de dominación. Se trata de sostener un marco institucional -legal y políticoque preserve la dominación y avale las actuales formas de producción del espacio.

Este contexto favorece la desinformación, el desconocimiento y el desinterés por comprender, en toda su complejidad y alcance, las actuales transformaciones territoriales, más aún cuando se presentan y difunden como irreversibles y fuera del alcance de los ciudadanos comunes, hecho que avala, por cierto, su desconexión con las mismas.

No hay duda de que este hecho constituye un formidable obstáculo en el camino de construcción de formas y mecanismos contrahegemónicos de resistencia y lucha. ¿Es posible crear instituciones que respondan a 
valores contrahegemónicos, por ejemplo, organizaciones sociales dirigidas a preservar su autonomía e independencia del estado y a comprometerse con otras prácticas de vida y consumo?

Estos casos existen y es necesario profundizar su conocimiento y difundir sus prácticas, especialmente porque observamos que hay un campo fértil generador de resistencias y conflictos. Así sucede con el que se vincula con las grandes transformaciones territoriales relacionadas con la reprimarización de la economía en el Cono Sur, con la agriculturización centrada en el monocultivo de soja.

Recuperar el control del territorio, de un territorio sobre el cual ejercer derechos consuetudinarios de vida y de trabajo, sólo puede lograrse a partir de gestar otro poder, un poder contra hegemónico, alternativo, producto de la participación, la movilización, la organización y la resistencia social que en muchos territorios y ámbitos locales se corresponde con su población mayoritaria, frecuentemente postergada y marginal.

Por su parte, la construcción de poder alternativo exige la deconstrucción de los variados valores y creencias que son parte y sostienen al sistema capitalista. Actualmente observamos que desde diferentes territorios de Latinoamérica aparecen muchas formas de oposición al avance depredador del modelo extractivista. Por ello, es necesario avanzar en su conocimiento más profundo, buscando identificar cuáles son las formas institucionales asociadas con la constitución de un poder contrahegemónico.

Para seguir en este camino de análisis, nos detendremos en un conocido caso localizado en el norte de la provincia de Salta y vinculado con el despojo social y ambiental resultante de la sojización.

\section{El “caso Pizarro” y el accionar del poder}

El caso Pizarro localizado en General Pizarro, en el departamento de Anta al noreste de Salta, es un ejemplo de desconocimiento intencionado de parte del poder político de leyes, de derechos y de aplicación de mecanismos dilatorios, y, en relación con los demás sectores, es un ejemplo de respuesta y movilización de organizaciones sociales, ambientalistas e indígenas, de alcance nacional e internacional (junto con el apoyo de ONGs, instituciones públicas y privadas). El caso Pizarro consistió originalmente en una protesta por la ley provincial 7274 del 2003, la cual desafectaba dos lotes fiscales (el 32 de 5298 ha y el 33 de 20.028 ha) de la categoría de área natural protegida y autorizaba su venta subvaluada a terceros $\underline{43}$.

La ley de desafectación fue enviada por el gobernador Juan Carlos Romero a la legislatura provincial y allí fue aprobada por dos tercios de los senadores y diputados (La Nación, 23-10-2004). Los motivos aducidos eran que se requería ese dinero para la reparación de las rutas provinciales 5 y 30 노․

El área desafectada no sólo es ecológicamente frágil sino que estaba habitada desde tiempos ancestrales por una comunidad wichi compuesta por 18 familias y numerosas familias de campesinos criollos $\underline{45}$ (Buliubasich, y Rodriguez, 2013; Bianchi, y Couto, 2013).

Los hechos asociados al caso Pizarro fueron desencadenantes de múltiples procesos territoriales centrados en la provincia de Salta. Uno de los más trascendentes fue la Ley de Bosques 26.331, que luego de muchas tratativas se dictó a fines de 2007 y que obligaba a un Ordenamiento Territorial de los Bosques Nativos (OTBN) en todo el país como condición para autorizar desmontes.

Sin embargo, en casi todas las provincias los gobiernos y los sectores de capital interesados en la deforestación idearon mecanismos para subvertir sus normativas y/o su aplicación. En Salta, por ejemplo, en el último cuatrimestre de 2007 se aceleraron las autorizaciones de desmonte, en particular en los departamentos de Anta, San Martín y Orán: "en una carrera vertiginosa, la Secretaría de Medio Ambiente y Desarrollo Sustentable (SEMADES), logró autorizar la cifra de 185.372,51 hectáreas en noviembre de ese 
año” (Buliubasich y Rodriguez, 2013, p. 176).

Diferentes documentos, medios y diarios registraron avances y retrocesos a lo largo de los años; se sucedían cautelares que suspendían desmontes con desmontes que desconocían dichas suspensiones, y así en un continuado ir y venir de acciones judiciales y prácticas depredatorias.

Las medidas cautelares que luego no se efectivizaban eran una constante. Por ejemplo, bajo el título "Detienen un desmonte en Salta”, y el subtítulo de "protesta ecologista”, Clarín publicó el 27 de julio de 2004:

El gobierno salteño ya preadjudicó las 16.275 hectáreas que tiene la reserva, a las empresas CUREL, MSU, S.A. y Miguel Ragone, que ofrecieron \$9.615.000 [aproximadamente u\$s 3.200 .000 de aquella fecha].

Ni bien concluyó el acto licitatorio, Greenpeace y las fundaciones Vida Silvestre, y Ambiente (FUSA) y Recursos Naturales (FARN) presentaron una medida cautelar para frenar la venta definitiva de los lotes de la reserva.

"Esto se va a conocer en todos los rincones del planeta mediante una ciberacción. Solicitamos a los usuarios de internet que exijan a las embajadas y consulados argentinos que frenen los desmontes" [Emiliano Ezcurra, referente de Greenpeace].

Por su parte, La Nación del 23 de octubre de 2004, en el marco de la autorización desenfrenada de desmontes titula: "Polémico desmonte en Salta. General Pizarro quedaría expuesto a graves inundaciones y a recibir masas de lodo desde las laderas de las sierras si se elimina el bosque en la zona vendida de los lotes 32 y 33”, e informa las opiniones de distintos referentes. Por un lado, de científicos y técnicos de la Universidad de Salta -UNSA- y del INTA, quienes en general plantean los riesgos ambientales y sociales de estos desmontes, ya entonces muy avanzados. Y, por otro, de funcionarios de gobierno, que desautorizan los informes de la UNSA afirmando que no es un trabajo con base científica sino sólo político, por estar la Universidad contra el gobernador Romero, a lo que agrega un discurso productivista que sostiene que la política provincial busca alentar la producción dentro de criterios de desarrollo sustentables.

Según Bianchi y Couto (2013, p. 223) lo que ha quedado finalmente del caso Pizarro son: a) 5.000 ha desmontadas para cultivo de soja; b) una comunidad wichi -Eben Ezer- que habita en un espacio de 800 ha, lo que le impide mantener sus prácticas anteriores de recolección y caza (realizadas en una superficie de 5000 ha) y que la lleva al aislamiento y al aumento del individualismo; c) una reserva Pizarro que se prometió y no se ha reconstruido; y d) familias de criollos que viven de forma precaria en superficies reducidas, muchas sin alcanzar su sustento.

Asimismo, estas autoras critican a Greenpace y Vida Silvestre. En primer lugar, porque en sus demandas priorizaron más la preservación del ambiente que los derechos y demandas de la población wichi y criolla. Y, en segundo lugar, porque desistieron de su presentación ante la justicia nacional (Corte Suprema de la Nación) y aceptaron el acuerdo propuesto por Parques Nacionales de creación de una nueva área protegida (que no ha avanzado) y la entrega de 800 ha a los wichis, que no les representa una solución a sus problemas.

A pesar de este panorama poco alentador, vale mencionar que las autoras reproducen un pensamiento de un dirigente de la Asociación de Pequeños Productores del Chaco Salteño (APCHS), Alfredo Riera, que da cuenta del nivel de comprensión de estos sectores y de la conciencia que la resistencia genera. Lo cual evidentemente es un capital social en la conformación de un poder alternativo:

Lamentablemente, todo esto no tiene ningún tipo de peso o valor para la justicia o los empresarios, que vienen de afuera reclamando supuestos derechos legales y en nombre de un desarrollo 
milagroso, que no incluye, sino que sólo ofrece expulsión y miseria a los campesinos que echan de sus tierras, pero que en honor a la verdad poco les importa el desarrollo y nuestros derechos adquiridos. Sólo les interesa realizar su gran especulación inmobiliaria y financiera a costa de nuestras familias y nuestras tierras. (Bianchi y Couto, 2013, p. 230).

A tan lúcida expresión sobre los sectores de poder empresariales queremos sumarle lo que el caso Pizarro revela o nos muestra en relación con el rol del estado. Aquí, el estado (ámbito de arbitraje, de conciliación, de búsqueda del equilibrio entre sectores, de promoción de la equidad y defensa de los sectores más desprotegidos, según el discurso dominante) claramente protege al poderoso, a la actividad privada sojera y desprotege a los más vulnerables social y ambientalmente. Los derechos de los más débiles: la comunidad wichi y los campesinos criollos (que además habitan en una zona de mucha fragilidad ambiental) son avasallados por el propio estado, que ni siquiera respeta derechos legalmente adquiridos y reconocidos históricamente, y en diferentes estamentos y jerarquías legales. $\underline{46}$

Es el propio estado el que no cumple con las leyes y convenios creados para regular la actividad socioeconómica: este estado no arbitra entre sectores en disputa, no regula, ni hace cumplir la ley, ni tampoco cumple él mismo las leyes que su función le obliga a resguardar. Este estado opera a favor de los sectores dominantes, hegemónicos, abandona al más débil y transgrede las leyes: es claramente un infractor en todos sus niveles: ejecutivo, legislativo y judicial. Este estado más que aliarse se subordina al poder hegemónico.

\section{Lineamientos para reflexionar e investigar}

Lo señalado hasta aquí muestra las profundas transformaciones territoriales que resultan de la expansión de los agronegocios y, en particular, de la reprimarización de la economía (principalmente asociada con la sojización).

Estas se expresan en:

i. Acaparamiento y concentración de la tierra, despojo de recursos naturales, aumento de los conflictos por la tierra y medioambientales.

ii. Expulsión de la población de su hábitat y migración hacia zonas o áreas marginales de ciudades medias y grandes.

iii. Vulnerabilidad ambiental asociada a la agriculturización, la deforestación, la desertificación y la pérdida de biodiversidad.

iv. Contaminación del ambiente en general y del agua en particular con agentes químicos, plaguicidas, pesticidas y múltiples agroquímicos causantes de enfermedades y muertes (empezando por la población -rural o urbana- que habita y vive en las zonas donde opera el agronegocio).

v. Desinterés, desatención y desaparición de las prácticas productivas y culturales de la población local y de las comunidades originarias.

vi. Imposición de las prácticas y valores de la cultura occidental en territorios rurales y de población originaria.

vii.Judicialización de la protesta social, persecuciones y asesinatos de líderes campesinos.

viii.Alianza y/o complicidad del estado con los sectores empresarios de poder en resguardo de los procesos de sojización.

ix. Incumplimiento y violación de leyes, convenios y reglamentaciones -provinciales, nacionales e internacionales- tanto por parte del sector empresario como del estado, que implican la vulneración de los derechos adquiridos por campesinos, pequeños productores, población originaria. 
Todas estas acciones se traducen en un profundo quiebre en la forma de vida de los pueblos y localidades a las que llegan inversores e interesados en tierras destinadas a la producción sojera.

En la mayoría de los territorios alcanzados por los intereses de capitales locales y del capital global conectados con la producción de soja, la organización espacial resultante se torna más desigual y regresiva que la precedente, por sus formas pronunciadamente excluyentes -intensivas en capital y de menor ocupación laboral- que traen consecuencias que afectan la seguridad y la soberanía alimentaria, la salud humana y el medioambiente. Esto en el largo plazo termina perjudicando a toda la sociedad y no sólo a algún sector particular.

Esta organización espacial (que permite la valorización del capital hegemónico a escala global, que domina a partir de un modelo sostenido en la exportación de bienes primarios, con precios fuera del control local y/o nacional y, frecuentemente, especulativos y en alza casi regular) configura territorios que expresan relaciones de poder espacializadas en las que el poder hegemónico aplica su capacidad excedente, asegura su proceso de acumulación y viabiliza su propia continuidad y la del capitalismo como sistema.

Las transformaciones territoriales (económicas, productivas, tecnológicas, sociales, institucionales, espaciales) resultantes de la hegemonía neoliberal limitan fuertemente las posibilidades de acciones y políticas que pretendan un tipo de desarrollo socialmente más incluyente y menos depredatorio, espacial y ambientalmente ${ }^{47}$. A la vulnerabilidad del modelo se suman los condicionamientos estructurales instalados y difíciles de remover (leyes, desregulaciones, privatizaciones, acuerdos internacionales, etc.) que condicionan el accionar político de los gobiernos en general, y de las organizaciones y actores locales que buscan otras alternativas de desarrollo.

Esto no impide reconocer que, de todos modos, la acumulación neoliberal por desposesión, por especulación financiera está y ha estado muy lejos de ser un proceso lineal, por el contrario, siempre se ve atravesada por conflictos y crisis recurrentes en diferentes ámbitos geográficos del mundo. Esto mismo sucede con la propia naturaleza de la financiarización de la economía perpetuamente vulnerable en relación a la producción de valor de la actividad industrial y agrícola (Harvey, 2009, p.63). La recurrencia cada vez más frecuente de las crisis, junto a la magnitud de los conflictos sociales que generan y a la diversidad de reacciones y movimientos sociales contestatarios que emergen, da cuenta de que tampoco la historia del desarrollo es lineal y de que la esperanza de alcanzar otros horizontes de desarrollo es posible.

\section{Notas}

1 Este trabajo se enmarca dentro de la temática de los proyectos que dirijo: UBACyT 2016 (010031); PIP Conicet 2012 (0273). PICT FONCyT-Agencia 2015 (0653).

$\underline{2}$ Agradezco a dos referatos anónimos que contribuyeron con sus comentarios a mejorar el contenido del presente trabajo.

$\underline{3}$ Feedlot (o engorde en corral) es una palabra inglesa de uso común en la ganadería y que refiere a un método dirigido a intensificar la producción mediante el encierro de los animales en corrales para alimentarlos en comederos.

$\underline{4}$ Situaciones tratadas en este trabajo y originadas en estudios y referencias judiciales y periodísticas.

$\underline{5}$ Este trabajo pretende contribuir a la discusión académica sobre la cuestión territorial y la concepción del territorio, desde el campo de las ciencias sociales en general y de la geografía en particular. Un análisis al respecto puede consultarse en Manzanal (2007 y 2014). 
6 Por reprimarización entendemos un proceso basado en la actividad primaria (por ejemplo producción de soja, de palma, extracción minera) y que comprende sus encadenamientos productivos, tecnológicos, societarios, financieros. Se trata de actividades vinculadas a través de procesos de extracción, transformación, industrialización, comercialización, servicios, finanzas. Las estadísticas tradicionales sobre producto bruto son insuficientes para identificar este fenómeno.

$\underline{7}$ Estas situaciones surgen de diferentes investigaciones (propias y de terceros) realizadas a partir de estudios de caso y trabajo de campo.

8 Paéz (2016, p. 140) menciona que hay diferentes hipótesis vinculadas con el origen de este boom de precios y que las mismas combinan elementos de demanda (aumento de la demanda de soja desde China), de oferta y financieros.

$\underline{9}$ Los sectores empresariales del agro en este conflicto contaron con el apoyo de un sector familiar, pequeño y medio agrupado en la Federación Agraria -FA- (cuando en años anteriores FA había colaborado en temas de agricultura familiar con el gobierno de los Kirchner). Diversas razones explican el nuevo posicionamiento de FA (relaciones comerciales y rentísticas entre sectores empresariales y pequeños y medianos productores; intereses de ámbitos locales, intereses políticos; el boom de los precios de los commodities en el mercado internacional).

10 Ver http://www.ambito.com/diario/noticia.asp?id=819800 (15-12-15).

11 Precisamente, La Nación y el Cronista del 21-3-2017 lo confirman con esta información: los representantes del complejo oleaginoso-cerealero anunciaron que las inversiones del sector realizadas en 2016 y las en curso en 2017, sumarán un desembolso de US\$ 1700 millones. Monto que, según la Cámara de la Industria Aceitera (Ciara) y el Centro de Exportadores de Cereales (CEC), supera todo los US\$ 1230 millones invertidos por las empresas del rubro en los ocho años que gobernó Cristina Kirchner.

12 Este plan fue presentado originalmente en el 2010 por la presidente Cristina Kirchner y decía textualmente: "aumento de la superficie sembrada para soja de 18,3 millones de ha en 2010 a 22 millones de ha en 2020, representando un crecimiento del 20\%" (pag.91); "aumento de la superficie cosechada para soja de 18,1 millones de ha en 2010 a 21,5 millones de ha en 2020, representando un crecimiento del 19\%” (p. 93); "aumento en la producción de soja de 52,7 millones de tn en 2017 a 71 millones de tn en 2020, representando un crecimiento del 35\%.” (p. 97). PEA ${ }^{2}$ (2010)

$\underline{13}$ En http://www.fyo.com/especiales/soja14-15/siembra (19-1-16): "El área destinada a la siembra de soja se ubicaría entre los 20,6 y 20,9 millones de hectáreas según datos oficiales de la Bolsa de Cereales de Buenos Aires y Bolsa de Comercio de Rosario, durante la campaña 2014/15. De concretarse esta estimación se registraría un incremento interanual del 1,2 \% y un nuevo récord de implantación de oleaginosa en nuestro país. Este número responde, fundamentalmente, a una notable reducción en el área de siembra de otros cultivos de verano sustitutos (productivamente hablando) como es el caso del maíz”.

14 Sevares (2014, p.105) al referirse al accionar del estado chino dice: "Las compras chinas son parte de la estrategia oficial de asegurarse la provisión de alimentos, con inversiones en la producción y el comercio y, en particular, de participar en la comercialización internacional de granos, en la cual China es uno de los principales compradores y el primero en el caso de la soja”.

15 Paulo Tavares es uno de los expertos convocados por el proyecto antropoceno en la Haus der Kulturen der Welt (Casa de las Culturas del Mundo) de Berlín donde se celebró un encuentro internacional para debatir sobre el futuro de nuestro planeta modificado por la presencia, a veces agresiva, del ser humano. Entrevista fue reproducida por $\tilde{N}$, Clarín, el 18-6-2013. 
16 Ver http://www.lapoliticaonline.com/nota/49545/ (05-08-2014).

17 Ver http://www.lapoliticaonline.com/nota/49545/ (05-08-2014).

18 http://www.lanacion.com.py/articulo/78110-el-explosivo-coctel-de-la-distribucion-de-la-tierra-enparaguay-detonante-de-la-crisis-politica.html (01-08-2014).

19 Así lo sostiene Aníbal Carrillo Iramain (candidato a presidente por el Frente Guasú, alianza que apoya al gobierno del desplazado Fernando Lugo) en una entrevista realizada por Página 12, el 18-3-2013. En dichas elecciones, celebradas el 21 de abril 2013, el partido colorado, nacionalista y conservador, vuelve al poder con el empresario Horacio Cartés como presidente (partido estrechamente aliado, desde sus políticas públicas a los intereses de los agronegocios).

20 La Coordinadora de Derechos Humanos del Paraguay (Codehupy) señaló que con la muerte de un nuevo dirigente Benjamín Lezcano, el 20-02-2013, suman 129 los asesinatos en la lucha por la tierra desde 1989. http://www.radiomundoreal.fm/Plan-de-exterminio-6481 (01-08-2014).

$\underline{21}$ http://quepasoencuruguaty.org/la-matanza-de-curuguaty-2/ (01-08-14). Este artículo afirma que la sociedad se pregunta: ¿qué pasó en Curuguaty? Y que el gobierno debería ser el principal interesado en aclarar los hechos. Y, sin embargo, "es una matanza mal investigada, que se puede convertir en una cruz que nunca abandonará a quienes, con la excusa de Curuguaty, perpetraron la aventura del juicio político a Fernando Lugo".

$\underline{22}$ Es el caso de obras -públicas y privadas- de infraestructura; construcciones inmobiliarias, industriales, financieras, comerciales, de servicios y civiles; transporte de carga y de pasajeros, individual y colectivo; plantas de producción e innovación en maquinarias, nuevas tecnologías y desarrollos de investigación. En este mismo campo, otras transformaciones territoriales directas resultan del accionar de la población, en relación a su localización y sus movimientos y traslados (tanto por nuevos empleos y nuevas y diversas actividades, como por actividades y población desplazada, por quiebras, traslados, desalojos, desempleos). Nuevas carreteras, puertos, industrias de trituración, bancos, concentran su localización en ciudades que se tornan centrales para el desempeño de la actividad sojera y conjuntamente pequeños pueblos y ciudades adquieren una dinámica nueva e importante como resultado de: a) el conjunto de servicios y comercios que se localizan en ellas vinculados con la expansión de la soja; y b) la nueva población conformada por muchos ex productores que arriendan sus campos para la producción de soja (a pools de siembra o a otros productores) y se trasladan a vivir en estas ciudades, sea de la renta de sus campos o sumando otras actividades. Así sucede en ciudades como San Lorenzo en la provincia de Santa Fe; o Presidencia Roque Saenz Peña, Villa Ángela, Charata, en la provincia del Chaco, Argentina. Mientras, a veces paralelamente, otros ámbitos espaciales se despueblan, pierden sus principales actividades, su comunicación con otros centros, o se ven afectados por la deforestación y la pérdida de biodiversidad circundante, o por el desplazamiento de sus principales cultivos (como maíz, trigo, ganadería, lechería). Todo lo cual responde a la afirmación de que la soja conlleva a producir un campo sin productores agrícolas.

$\underline{23}$ La hidrovía Paraná-Paraguay constituye uno de los 10 ejes de integración y desarrollo que IIRSA propone en Sudamérica. Su costo se calculó en 1 billón de dólares. Es una mega obra de ingeniería que abarca unos 3.440 km. continuos entre el Puerto Cáceres en el extremo Norte (Brasil) y el Puerto de Nueva Palmira en el extremo Sur (Uruguay), http://limno.fcien.edu.uy/publications/hidrovia.html - (16-7-2014). Esta obra busca aumentar la capacidad y frecuencia permanente, diurna y nocturna, de tráfico de productos, principalmente agrícolas (soja), minerales (hierro y manganeso) y combustible, a través del sistema fluvial Paraguay-ParanáUruguay-Río de la Plata. Un estudio de la Coalición Holandesa de la Soya (2008, p. 15) sostiene que estas obras "sólo serán rentables si Argentina incrementa su producción de soja en grano a 100 millones de toneladas al año”. Es decir, casi el doble de lo que fue la cosecha de soja en Argentina del 2014. Otro de los 
ejes de integración y desarrollo de IIRSA, donde la comercialización de la soja también está presente (en este caso hacia el Pacífico) es el eje de Capricornio que comunicaría las regiones del NEA y NOA de Argentina con zonas de Bolivia, Brasil, Chile y Paraguay http://www.iirsa.org/Page/PageDetail? $\underline{\mathrm{id}=117 \& \text { menuItemId=57 }}(16-07-2014)$.

$\underline{24}$ Desde luego que la marginación social urbana se origina en procesos muy anteriores en la historia argentina. Se puede observar ya en la década de 1940, asociada a la industrialización sustitutiva. Pero en aquellos años, los trabajadores asentados en zonas marginales tenían opciones laborales, incluso empleo formal, en la propia industria en expansión o en sus servicios conexos. Esto no es lo que sucede actualmente..

$\underline{25}$ http://elpais.com/elpais/2014/06/23/planeta futuro/1403547065 012817.html (26-6-2014). Cabe aclarar que las “villas miserias" de Argentina corresponden a las “favelas” de Brasil, las “callampas” de Chile, entre otras terminologías locales. Por su parte, la provincia de Santiago del Estero se ubica entre las más pobres del país y se localiza en el noroeste.

$\underline{26}$ La actividad agropecuaria pampeana tiene históricamente un rol central en la provisión de alimentos, tanto en el orden interno como internacional. Su potencialidad productiva implica reconocidas ventajas comparativas del agro. De aquí que esta extensa región del Cono Sur haya sido definida como el "Granero del Mundo”, porque desde el siglo XIX su producción se ha destinado a la alimentación de gran parte de la población humana mundial. La pampa húmeda del Cono Sur es una región con precipitaciones superiores a los 500 mm/año y se expande por las llanuras de Argentina, Uruguay y Brasil (departamento Rio Grande do Sul).

$\underline{27}$ La agriculturización se caracteriza por procesos intensivos de producción agrícolo-ganadera, con desplazamiento de la ganadería de cría hacia zonas de menor aptitud agrícola, avance de la agricultura (entre ellas la producción de soja) sobre otras actividades productivas.

$\underline{28}$ El Gran Chaco es un área cultural sudamericana con una extensa planicie que se extiende al norte del Cono Sur, en territorios del norte de Argentina, Bolivia, Paraguay y centro-sur de Brasil, que alberga numerosa población originaria perteneciente a diversas etnias y una gran variedad de flora y fauna. En una superficie de un 1 millón de $\mathrm{km}^{2}$ es una de las regiones de mayor diversidad ambiental y biológica del planeta, con el área boscosa más grande del continente después de Amazonas. http://www.ambiente.gov.ar/? $\underline{\text { idseccion }=117}(25-07-2014)$

$\underline{29}$ http://www.dw.de/bosques-en-argentina-desplazados-por-la-soja/a-14965678 (24-7-2014).

\section{Clarín 30-4-2004}

$\underline{31} \mathrm{Al}$ respecto, tan sólo vale recordar la actividad de La Forestal que a finales del siglo XIX y gracias al desmonte indiscriminado de quebrachales del Chaco austral (norte de Santa Fe, sur del Chaco y noreste de Santiago del Estero) se convirtió en la primera productora de tanino a nivel mundial. https://es.wikipedia.org/wiki/La Forestal\#La devastaci.C3.B3n natural

32 La pampeanización se inicia hacia 1960, antes del boom de la soja e implica la expansión de la frontera agrícola y nuevas producciones (poroto, ganadería, pasturas) para zonas extrapampeanas.

$\underline{33}$ Ver mapa respectivo en http://www2.medioambiente.gov.ar/bosques/umsef/cartografia/default.htm (29-72014).

$\underline{34}$ No se dispone de información posterior a 2006, pero el avance continuado de la agriculturización y de los conflictos sociales en el Chaco por este tema, nos hace suponer que la tasa de pérdida anual de bosques tiene 
que haber aumentado.

35 En cambio poca prensa reciben las noticias vinculadas con los conflictos de las poblaciones originarias, campesinos y pequeños productores por problemas con: a) la tierra u otros recursos; b) el ambiente; c) la difusión de enfermedades y muertes asociadas a la fumigación con agroquímicos; d) los desalojos y la expulsión de campesinos y población originaria de sus tierras, aunque les correspondan por el derecho de usucapión. Son todas situaciones que en general tienen un origen común: la sojización con sus secuelas de deforestación, desertificación y pérdida de la biodiversidad.

36 La línea editorial de La Nación representa los intereses de los sectores tradicionalmente hegemónicos del país. Por esto es que, las afirmaciones de los expertos consultados llaman la atención, por ser francamente críticas hacia los procesos de sojización. Las mismas no condicen con la línea editorial a favor de la expansión de la soja y del avance de la frontera agraria. Todos los expertos sostienen que fue el libre funcionamiento de mercado el que ha conducido a esta situación de descontrol en el avance de la frontera. Observamos que este artículo fue publicado sólo en la edición impresa, no en la digital ni en el suplemento Campo, de alcance más restringido y para un público especializado. Al cual puede estar advirtiéndosele sobre un ciclo de difícil reversión, que podría desembocar en el fin de los buenos negocios realizados con la modalidad depredadora de población y naturaleza.

$\underline{37}$ Se trata de Roberto Casas del INTA, Ernesto Viglizzo del INTA y del CONICET y Jorge Adámoli, de la Facultad de Ciencias Exactas de la UBA.

38 Agricultura familiar (AF) más que un concepto constituye un término, una categoría genérica y heterogénea, de uso común desde la política y las políticas. Actualmente su amplia difusión y uso extendido surge de procesos de mediación y negociación entre diferentes actores involucrados. Por lo cual se trata, centralmente, de una categoría política, que engloba a muy variados actores, con diferentes prácticas productivas y culturales, diferentes accesos a tecnologías, recursos y capital. La cuestión que los asimila en una misma categoría es la presencia de trabajo familiar directo en el proceso productivo de la finca, predio o explotación (para una mejor y más comprensible caracterización véase Tsakoumagkos, 2013, pp. 14-18).

$\underline{39}$ Lo cual, por otra parte, conforma una realidad que no condice con las actuales políticas públicas (nacionales, regionales, latinoamericanas e internacionales) que ubican a la AF como el sostén de la seguridad y soberanía alimentaria, como la proveedora de los alimentos necesarios para enfrentar los problemas de la seguridad y soberanía alimentaria -SSA- de cada país (FAO, 2010). Consideramos que un referente al respecto es la experiencia de Brasil, que desde 2003 aplica el Programa de Adquisición de Alimentos -PAA- (FAO, 2010; Mielitz, 2010).

40 Eduardo Leguizamón introdujo en el país las sojas transgénicas RR y el germoplasma de trigo francés de alto rendimiento como presidente de Nidera Argentina. Dirigió esta empresa, líder en el sector, entre 1976 y 2001. También fundó Nidera Semillas y Nidera Fertilizantes. (La Nación, 26-4-14). Nidera está entre las 30 mayores exportadoras de cereales de Argentina que integran el centro de Exportadores de Cereales (CIARACEC), http://www.lapoliticaonline.com/nota/49545/ (05-08-2014). Nidera es una empresa holandesa del sector de producción y comercialización de cereales y materias primas. En Argentina se radicó hace cerca de 90 años (en 1929), y es líder en la producción de híbridos y semillas. Hace un par de años, el 51\% de su paquete accionario fue adquirido por la semiestatal China National Cereals, Oil and Foodstiffs (COFCO). Sevares, Julio (2014, p. 105).

41 El menor empleo resultante de la producción de soja por las nuevas tecnologías ha sido estudiado. La difusión de soja transgénica y siembra directa (como sucede en Argentina) implica menor cantidad de tareas. Por ello, la demanda de mano de obra resulta "un 30\% inferior en comparación con la agricultura convencional. Conjuntamente, exige mayores calificaciones de la mano de obra involucrada, debido a la 
incorporación de tecnologías de procesos que requieren un conocimiento integral del paquete tecnológico y del proceso productivo". http://www.uba.ar/encrucijadas/46/sumario/enc46-massoja.php

42 Cabe aclarar que territorial y/o territoriales refiere al territorio como producción social del espacio e implica lo social, lo económico, lo político, lo institucional, lo cultural, tanto en sus dimensiones materiales como simbólicas. Tienen su raíz en el concepto territorio que expresa relaciones sociales, de poder (Manzanal, 2007, pp. 33 y ss).

$\underline{43}$ La normativa que dio lugar a la protección como área natural tuvo su origen en 1995. Entonces, el Poder Ejecutivo de Salta, encabezado entonces por Roberto Ulloa del partido Renovador, declaró a través del decreto 3397/95 a los lotes fiscales 32 y 33 “Área natural provincial protegida”. Medida tomada para preservar una conjunción de ambientes distintos en una zona de transición entre la llanura chaqueña y las sierras subandinas: "Los distintos ambientes producen gran diversidad de especies de difícil repetición en el mundo” (Bianchi \& Couto; 2013, p. 213).

44 Suena contradictorio, aunque no lo es, la argumentación que sostiene que se venden las tierras porque se necesitan recursos para reparar las rutas, cuando recursos para vialidad deberían provenir del erario público, o bien podría ser, como en otras rutas, que fueran financiadas o a cargo de quienes las usan, en este caso las empresas comercializadoras de soja que circulan y la deterioran (Bianchi \& Couto, 2013, p. 214). El interés en esta nueva normativa legal era el acceso a nuevas tierras. Por ello esas argumentaciones son parte de la mitificación del discurso del poder.

$\underline{45}$ No hay acuerdo entre los medios en relación con el número de familias involucradas. Clarín (27-7-2014) menciona 34 familias de criollos y 11 de aborígenes que resistieron la decisión del gobierno de sacarlos del lugar en que vivían. La Nación (23-10-2004) afirma que 18 familias (más de 70 personas) conformaban la comunidad wichi Eben Ezer.

46 Derechos establecidos en la Constitución Nacional, en la de la provincia de Salta, en leyes provinciales y nacionales -de medio ambiente, de áreas protegidas, de defensa de la riqueza forestal y de la fauna silvestreen convenios internacionales contra la desertificación y protección de flora y fauna silvestre, etc. Bianchi \& Couto, (2013, p. 214).

47 Como es el caso de la diversidad de acciones de inclusión de la AF sistematizadas desde investigaciones y recopilaciones de organismos nacionales e internacionales (Caracciolo y Fontana, 2015; FAO, 2010 y 2014).

\section{Bibliografía}

Bianchi, S., y Couto, M. (2013). El caso `Pizarro’ (Salta): movilización y poder. En M. Manzanal y M. Ponce (Org.), La desigualdad ¿del desarrollo? Controversias y disyuntivas del desarrollo rural en el norte argentino (pp. 213-232). Buenos Aires: CICCUS.

Buliubasich, C., y Rodriguez, H. (2013). Política indígena y desarrollo rural en el contexto del ordenamiento territorial de bosques nativos en Salta. En M. Manzanal y M. Ponce (Org.), La desigualdad ¿del desarrollo? Controversias y disyuntivas del desarrollo rural en el norte argentino (pp.171-190). Buenos Aires: CICCUS.

Caracciolo, M., y Fontana P. (2015). Situación de la institucionalidad de apoyo a la innovación comercial y de los procesos de gestión comercial de la agricultura familiar en la Argentina. Buenos Aires: INTA - IICA.

Coalición Holandesa de la Soya (2008). Otra mirada sobre la soya. Buenos Aires: AIDE.

FAO (2010). Un programa de políticas públicas para la agricultura familiar. En $31^{\text {a }}$ Conferencia Regional de la FAO para América Latina y el Caribe. Ciudad de Panamá, Panamá, 26 al 30 de abril de 2010. 
FAO (2012). Pérdidas y desperdicio de alimentos en el mundo. Alcance, causas y prevención. Roma: FAO. FAO (2014). Agricultura Familiar en América Latina y el Caribe. Recomendaciones de política, Santiago de Chile.

Harvey, D. (2009). O novo imperialismo (3 ${ }^{\mathrm{a}}$ edición). San Pablo: Ediçoes Loyola.

Manuel-Navarrete, D. et al. (2005). Análisis sistémico de la agriculturización en la pampa húmeda argentina y sus consecuencias en regiones extrapampeanas: sostenibilidad, brechas de conocimiento e integración de políticas. Series Medio Ambiente y Desarrollo, 118. Santiago de Chile: CEPAL.

Manzanal, M. (2014). Desarrollo. Una perspectiva crítica desde el análisis del poder y del territorio. Realidad Económica, 283. Buenos Aires: IADE

Mielitz, C. (2010). Agricultura familiar no contexto das políticas públicas brasileiras. En M. Manzanal y G. Neiman (comp.), Las agriculturas familiares del Mercosur. Trayectorias, amenazas y desafíos (pp. 61-78). Buenos Aires: CICCUS.

Moraes, A. (2005). Ideologías Geográficas. Espaço, cultura e Política no Brasil (5ª edición). San Pablo: Annablume Editora.

Naharro, N., Alvarez, M. A., y Klarik, M. (2009). Territorio en disputa: reflexiones acerca de los discursos que legitiman la propiedad de la tierra en el Chaco salteño. En M. Manzanal y F. Villarreal, El desarrollo y sus lógicas en disputa en territorios del norte argentino (pp. 133-154). Buenos Aires: Ciccus,

MAGyP (2010). PEA², Plan Estratégico Agroalimentario y Agroindustrial. Participativo y Federal 20102020, Ministerio de Agricultura, Ganadería y Pesca de la Nación, Argentina.

Paéz, S. M. (2016). Soja en Argentina a principios del siglo XXI: el sistema agropecuario y la competencia por el uso del suelo productivo. Cuadernos de Economía Crítica -CEC- Año 3, 5, 135-169.

Portes, A. (2006). Instituciones y desarrollo. Una revisión conceptual. Cuadernos de Economía, 25(45), 1352.

REDAF (2010). Conflictos sobre la tenencia de tierra y ambientales en la región del Chaco argentino, $2^{\circ}$ informe. Reconquista: REDAF

Secretaria de Ambiente y Desarrollo Sustentable de la Nación (2012). Informe sobre el estado del ambiente 2012. Buenos Aires: Jefatura de Gabinete Presidencia de la Nación Argentina.

Sevares, J. (2014). Inversiones chinas en América latina: una relación económica emergente. Realidad Económica, 284, 96-112.

Tsakoumagkos, P. (2013). La problemática agraria en la Argentina. Cuestiones y perspectivas de la pequeña producción. Realidad Económica, 280, 13-25.

\section{Fuentes informativas, periodísticas, páginas www}

Diarios argentinos (Clarín, La Nación, Pagina 12)

DW -Deutsche Welle-http://www.dw.de/bosques-en-argentina-desplazados-por-la-soja/a-14965678 (24-72014)

El País. Planeta Futuro (26-6-2014) http://elpais.com/elpais/2014/06/23/planeta futuro/1403547065 012817.html 
El Universo, 9-5-2014 http://www.eluniverso.com/vida-estilo/2014/05/09/nota/2939331/40-alimentosproducidos-nivel-mundial-se-desecha-indica-fao

Encrucijadas $\mathrm{N}^{\circ}$ 46. Nota de Roberto Benencia titulada: “Más soja, menos trabajo?” http://www.uba.ar/encrucijadas/46/sumario/enc46-massoja.php (02-08-2014)

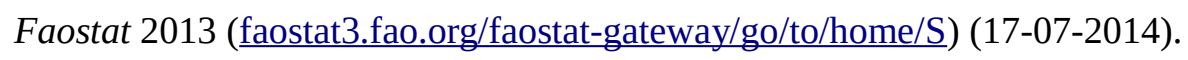

Grain (2013). "La república unida de la soja recargada”. http://www.grain.org/es/article/entries/4739-larepublica-unida-de-la-soja-recargada (12-6-2013). http://quepasoencuruguaty.org/la-matanza-de-curuguaty$\underline{2 /}(01-08-14)$

IIRSA, Iniciativa para la Integración de la Infraestructura Regional Suramericana http://www.iirsa.org/Page/PageDetail?id=117\&menuItemId=57 (16-07-2014).

La Nación, 3-11-2013, http://blogs.lanacion.com.ar/ecologico/cambio-climatico-2/se-extiende-la-fronteradel-riesgo-agricola-en-el-pais/

La Nación (Diario de Paraguay) http://www.lanacion.com.py/articulo/78110-el-explosivo-coctel-de-ladistribucion-de-la-tierra-en-paraguay-detonante-de-la-crisis-politica.html (01-08-2014)

La Politica Online, http://www.lapoliticaonline.com/nota/49545/(05-08-2014).

Radio Mundo Real Paraguay http://www.radiomundoreal.fm/Plan-de-exterminio-6481 (01-08-2014)

Secretaría de Ambiente y Desarrollo Sustentable de la Nación, Argentina. http://www.ambiente.gov.ar/? $\underline{\text { idseccion}=117}(25-07-2014)$

UDELAR, Facultad de Ciencias, Guillermo Chalar Marquisá (16-07-2014) http://limno.fcien.edu.uy/publications/hidrovia.html 